\title{
RESEARCH
}

Open Access

\section{Unstimulated whole salivary flow in Sjögren's Syndrome: systematic literature review and meta-analysis}

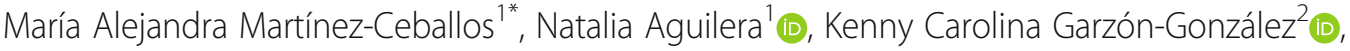 \\ Jairo Cajamarca-Baron ${ }^{3}$ (D) Juan Pablo Alzate-Granados ${ }^{1}$ (i) and Adriana Rojas-Villarraga ${ }^{4}$ (i)
}

\begin{abstract}
Background: Sjögren's Syndrome compromises the exocrine function, producing xerostomia and xerophthalmia. It can appear as an isolated condition or associated with other autoimmune diseases (polyautoimmunity). The Unstimulated Salivary Flow rate (UWSF) is used to quantify saliva production. There is no objective evidence to differentiate the values in patients with Sjögren's versus healthy people or patients with non-Sjögren's sicca. The objective of the present review was to evaluate the UWSF in patients with Sjögren's syndrome in comparison to controls (healthy and non-Sjögren's sicca patients).
\end{abstract}

Methods: A systematic literature review was carried out (PRISMA guidelines). Analytical observational studies of cases and controls, cross-sectional studies, cohort studies and randomized clinical trials (including healthy controls) were considered. The Medline/OVID, Lilacs, Embase, and Cochrane/OVID databases were consulted. MeSH, DeCS, keywords, and Boolean operators were used. The meta-analysis (RevMan 5.2) was done through the random-effects model [mean difference (MD)]. Level and quality of evidence were evaluated by the Oxford Center Levels of Evidence and Joanna Brigs list respectively.

Results: Thirty-two articles were included (20 were case-control studies, 6 were cross-sectional, 2 prospective cohort, 2 retrospective cohort, and 2 studies were abstracts) and 28 were meta-analyzed. The unstimulated whole salivary flow rate in the Sjögren's group was lower than in controls (healthy and patients with non-Sjögren Sicca syndrome) (MD-0.18 ml/min; $95 \% \mathrm{Cl},-0.24$ to -0.13 ; Chi $^{2}$-P-value $\left.<0.00001\right)$. Heterogeneity was $97 \%$ and there was publication bias (funnel plot). The level of evidence was mostly 3 or 4 . The quality of evidence was met (97\% of items valued).

Conclusion: For the first time, the unstimulated whole salivary flow rate is found to be lower in patients with Sjögren's syndrome compared to controls (healthy and non-SS sicca) through a meta-analysis.

Trial registration: PROSPERO CRD42020211325.

Keywords: Sjögren's syndrome, Salivary glands, Xerostomia, Autoimmune diseases, Autoimmunity

\footnotetext{
* Correspondence: mariamace9@gmail.com

${ }^{1}$ Research Division Fundación Universitaria de Ciencias de la Salud (FUCS), Bogotá, Colombia

Full list of author information is available at the end of the article
}

(c) The Author(s). 2021 Open Access This article is licensed under a Creative Commons Attribution 4.0 International License, which permits use, sharing, adaptation, distribution and reproduction in any medium or format, as long as you give appropriate credit to the original author(s) and the source, provide a link to the Creative Commons licence, and indicate if changes were made. The images or other third party material in this article are included in the article's Creative Commons licence, unless indicated otherwise in a credit line to the material. If material is not included in the article's Creative Commons licence and your intended use is not permitted by statutory regulation or exceeds the permitted use, you will need to obtain permission directly from the copyright holder. To view a copy of this licence, visit http://creativecommons.org/licenses/by/4.0/ 


\section{Introduction}

Sjögren's Syndrome (SS) is a chronic autoimmune disease that compromises the function of the exocrine glands in the skin and mucosa of the eyes, mouth, etc. and it results in predominantly xerophthalmia and xerostomia [1]. SS could appear as an isolated disease (Primary Sjögren Syndrome (pSS)), or associated with another autoimmune pathology (Secondary Sjögren Syndrome (sSS)) such as autoimmune thyroid disease (15$30 \%)$, rheumatoid arthritis (4-31\%), systemic lupus erythematosus (9-19\%), and systemic sclerosis (14\%). Recently this association was named polyautoimmunity [2].

SS is among the most frequent systemic autoimmune rheumatic diseases. The prevalence is around 0.3 to 1 case per 1000 persons [3], and it has an annual incidence of 6.92 cases per 100,000 people [4]. It is a frequent condition in women with a 9:1 female/male ratio and a high frequency of diagnosis at the age of 50 [3].

The physio-pathological mechanisms of SS are unknown. However, the epithelial destruction of the exocrine gland by an abnormal T (especially Th1 and Th17) and $B$ cell response to specific auto-antigens such as Ro/ SSA and La/SSB (autoimmune epithelitis) is described. The etiology for the development of this disease is multifactorial and includes genetic, epigenetic, hormonal, and environmental factors [5].

SS is classified according to American College of Rheumatology/European League against Rheumatism (ACR/EULAR) criteria. It includes the presence of ocular (objective tests) or oral gland hypofunction (by means of sialometry), specific autoantibodies, and focal lymphocytic infiltrates in the minor salivary gland. The ACR/ EULAR criteria have to be applied to patients with suspected SS due to dry eye and dry mouth symptoms (at least one positive response from five established dryness questions), salivary gland enlargement, or extraglandular compromise (at least one item from ESSDAI (EULAR Sjögren's syndrome disease activity index)) [6].

Up to $80 \%$ of patients suffer dry eye and dry mouth symptoms, the key manifestations of SS. The clinical picture is also associated with systemic (e.g. asthenia and articular pain) or extraglandular manifestations in 40\% [3].

There are procedures that objectively measure saliva production. The sample can be taken from an isolated salivary gland or several that are combined during rest [Unstimulated Whole Salivary Flow (UWSF)] or with stimulation [Stimulated Whole Salivary Flow (SWSF)] [7]. The measurement of UWSF is a quick, easy, and non-invasive test, and it is an item in the classification criteria for SS. Recently, the EULAR developed recommendations for the management of Sjögren's syndrome with topical and systemic therapies [8]. They emphasized that the therapeutic approach to oral dryness should be driven by the baseline measurement of salivary glandular function (UWSF), and not by the patient's subjective feelings since environmental and personal stress factors may influence the subjective feeling of dryness.

The main concern here is the production of saliva measured by the UWSF. Several studies, including systematic literature reviews and meta-analyses have evaluated saliva production in patients with xerostomia in different non-SS autoimmune diseases such as systemic lupus erythematosus, type I diabetes mellitus [9], autoimmune thyroid diseases, oral lichen planus $[10,11]$, systemic sclerosis [12], juvenile idiopathic arthritis [13]. All of these have shown a lower rate of saliva production compared to healthy controls. Nevertheless, we were unable to find saliva production results for patients with SS as a primary disease in our search.

In the context of SS, a value of $\leq 0.1 \mathrm{ml} / \mathrm{min}$ is included in the ACR/EULAR SS criteria [14]. Nevertheless, this cut-off point went through a transition over a period of years, and it is included in or excluded from the different proposed international criteria [6, 14-20]. However, the justification for these changes is not clear in the literature even though it is a diagnostic criterion with the same weight as eye tests (Schirmer and ocular staining score) for an SS diagnosis. The established values in these criteria differentiated salivary gland hypofunction only in patients with sicca symptoms versus healthy controls, but not in patients with SS.

Therefore, in this systematic literature review and meta-analysis, the intention is to evaluate the saliva production through the UWSF in SS patients compared to non-SS patients with sicca symptoms and healthy controls in order to show objective differences between the diverse study groups.

\section{Materials and methods \\ Search strategy}

A systematic literature review was done to identify the articles that report UWSF values in patients with SS versus healthy subjects or patients with non-SS sicca symptoms. PRISMA guidelines [21] were followed for reporting systematic reviews and meta-analysis. Medline/OVID, Lilacs, Embase, and Cochrane/OVID were searched up to July 20th, 2020. Medical Subject Heading terms (MesH): "Adult," "Sjogren's Syndrome," "Sjogrens, " "Sjögren," "Sjögren's," "Sjogren," "Gougerot," "Gougerot-Sjogren," "Gougerot-Sjögren," "Primitive Gougerot-Sjögren," "Gougerot-Sjögren," "GougerotHouwers-Sjögren," "Unstimulated salivary flow," "USF," "Unstimulated whole salivary flow," "Whole unstimulated salivary flow," "Unstimulated saliva," "Basal salivary flow," "Sialometry," "Whole unstimulated salivation" were used. MeSH terms were crossed with keywords using boolean operators (OR, AND, NOT) and wild cards (Table 1). The search was not restricted by year, 
Table 1 Search Strategy

\section{Population:}

Adult [Mesh]

\section{Exposition:}

"Sjogren's Syndrome"[Mesh]

Sjögren's syndrome

Sjogren syndrome

Sjögren syndrome

Sjogren disease

Sjögren disease

Sjogren's disease

Sjögren's disease

Sjögren

Sjögren's

Sjogren

Sjogren's

Gougerot

Gougerot Sjogren

Gougerot Sjögren

Gougerot-Sjogren

Gougerot-Sjögren

Gougerot Sjogren syndrome

Gougerot Sjögren syndrome

Gougerot-Sjogren syndrome

Gougerot-Sjögren syndrome

Gougerot Sjogren disease

Gougerot Sjögren disease

Gougerot-Sjogren disease

Gougerot-Sjögren disease

Gougerot Sjogren

Gougerot Sjögren

Gougerot-Sjogren

Gougerot-Sjögren

Gougerot Sjogren syndrome

Gougerot Sjögren syndrome

Gougerot-Sjogren syndrome

Gougerot-Sjögren syndrome

Gougerot Sjogren disease

Gougerot Sjögren disease

Gougerot-Sjogren disease

Gougerot-Sjögren disease

Primitive Gougerot-Sjögren syndrome

Gougerot-Houwers-Sjögren syndrome

Gougerot-Houwers-Sjögren disease

\section{Outcome:}

Unstimulated salivary flow

USF
Table 1 Search Strategy (Continued)

\author{
Unstimulated salivary flow rate \\ Unstimulated whole salivary flow \\ Whole unstimulated salivary flow \\ Whole USF \\ Unstimulated saliva \\ Decreased unstimulated saliva \\ Unstimulated saliva measurement \\ Basal salivary flow \\ Basal sialometry \\ Unstimulated sialometry \\ Unstimulated whole sialometry \\ Whole unstimulated sialometry \\ Whole unstimulated salivation \\ "Salivary elimination"[Mesh]
}

\section{Search Strategy:}

1. Adult/exp

2. Adult.tw

3. Adults.tw

4. Sjogren's Syndrome/exp

5. (Sjogren's Syndrome).tw

6. Sjogrens.tw

7. Sjögren.tw

8. Sjögren's.tw

9. Sjogren.tw

10. Sjogren's.tw

11. Gougerot.tw

12. Gougerot-Sjogren.tw

13. Gougerot-Sjögren.tw

14. (Primitive Gougerot-Sjögren).tw

15. (Primitive adj3 Gougerot-Sjögren).tw

16. Gougerot-Houwers-Sjögren.tw

17. (Unstimulated salivary flow).tw

18. (Unstimulated adj3 salivary adj3 flow).tw

19. USF.tw

20. (Unstimulated whole salivary flow).tw

21. (Unstimulated adj3 whole adj3 salivary adj3 flow).tw

22. (Whole unstimulated salivary flow).tw

23. (Whole adj3 unstimulated adj3 salivary adj3 flow).tw

24. (Unstimulated saliva).tw

25. (Unstimulated adj3 saliva).tw

16. (Basal salivary flow).tw

27. (Basal adj3 salivary adj3 flow).tw

28. sialometry.tw

29. (Whole unstimulated salivation).tw

30. (Whole adj3 unstimulated adj3 salivation).tw 
language, or country of origin, but filters for species (humans) and ages (Adult) were applied. This review was registered in the international prospective registry of systematic reviews (PROSPERO) with registration number CRD42020211325.

\section{Inclusion criteria \\ Study design}

Analytical observational studies of cases and controls, cross-sectional studies, cohort studies and randomized clinical trials (including healthy controls).

\section{Population}

Patients 18 years of age or older, with sicca symptoms and SS diagnosis based on established criteria: ACR/ EULAR, AECG (American-European Consensus Group), and Fox et al. [14, 18, 22].

\section{Intervention}

UWSF measurement by any method of collection.

\section{Control group}

Patients with non-SS sicca symptoms and/or healthy subjects.

\section{Exclusion criteria}

Studies that compare with other autoimmune diseases. Pregnant women.

\section{Data extraction and quality assessment}

Two reviewers (NA and CG) independently screened titles and abstracts to determine the initial eligibility. After the screening phase, the same two reviewers evaluated the selected abstracts and full text independently (software Mendeley Desktop v1.19.2) to evaluate their inclusion based on the established criteria. Another two reviewers (ARV and MAM) resolved disagreements by discussing them until they reached a final consensus.

The level of evidence and methodological quality assessment was done by two independent reviewers (NA and ARV) using the Oxford Centre for Evidence-Based Medicine 2011 Levels of Evidence Question (OCEBM) [23] and Joanna Briggs Checklists [24].

Two independent reviewers (MAM and JPA) extracted the data using a Microsoft $\operatorname{Excel}^{\odot}$ (v. 2013) database. The UWSF measures were unified to $\mathrm{ml} / \mathrm{min}$, and the values reported in the subgroups were averaged. The central tendencies and dispersion measures (mean and standard deviation) were imputed. The expert reviewer (ARV) independently verified the abovementioned values. Two authors (JPA and MAM) registered the extracted data in the Review Manager Software $5.2^{\circ}$ and the two authors' inconsistencies were corrected.
The following data were taken out: First author name, study year, study design, objective of the study, country, number of cases with SS (primary SS and SS with polyautoimmunity), number of controls (non-SS sicca symptoms and/or healthy subjects), number of women, age, disease duration, UWSF, stimulated salivary flow rate (SSF), comorbidities, and pharmacological therapy in cases and controls.

\section{Data analysis}

Statistical analysis was done with Review Manager Software $^{\oplus}$ (RevMan 5.2). After that, data from the articles chosen were merged using the random-effects model (DerSimonian and Laird) due to the studies' high heterogeneity (sample size, saliva collection technique, and classification criteria for SS) to establish a global summary measure (overall effect).

The meta-analysis measurement considered the possible effects of the exposure as an average of ranges. The final effect size was presented as a mean difference with a confidence interval and the respective $P$-value. The forest plot was used to show the weight of each study.

Heterogeneity was assessed using the $\mathrm{Chi}^{2}$ statistic, and the $\mathrm{I}^{2}$ (Higgins). $\mathrm{I}^{2}$ values of 25,50 , and $75 \%$ corresponding to low, medium, and high levels of heterogeneity respectively were considered. In addition, substantial heterogeneity was established if the value of the $\mathrm{Chi}^{2}$ test was less than one. To evaluate the robustness of results and to identify the potential sources of heterogeneity, a sensitivity analysis and a subgroup analysis were done. Publication bias was graphically assessed by visual inspection of the funnel plot and confirmed using the Egger's regression test.

\section{Results}

\section{Search results}

The first search identified 569 articles. Two reviewers evaluated the studies by title and abstract and chose 133 without duplicates. The second round was done based on full text and 32 articles were selected. There was a total of 28 studies included in the quantitative synthesis. Figure 1 shows the PRISMA flow-diagram. Causes of exclusion are detailed in Table 2.

Of the articles included by full text, 20 were casecontrol studies, 6 were cross-sectional, 2 prospective cohort, 2 retrospective cohort, and 2 studies were abstracts and there was not enough information to establish the type of study and quality of evidence. The level and quality of evidence are shown in Table 3. The level of evidence for most of the articles was 3 or 4 using OCEBM guidelines and the quality of evidence was around $97 \%$ for all articles.

The 32 articles included correspond to approximately 3262 patients. Of these, $46.8 \%$ (1528) were cases, and 


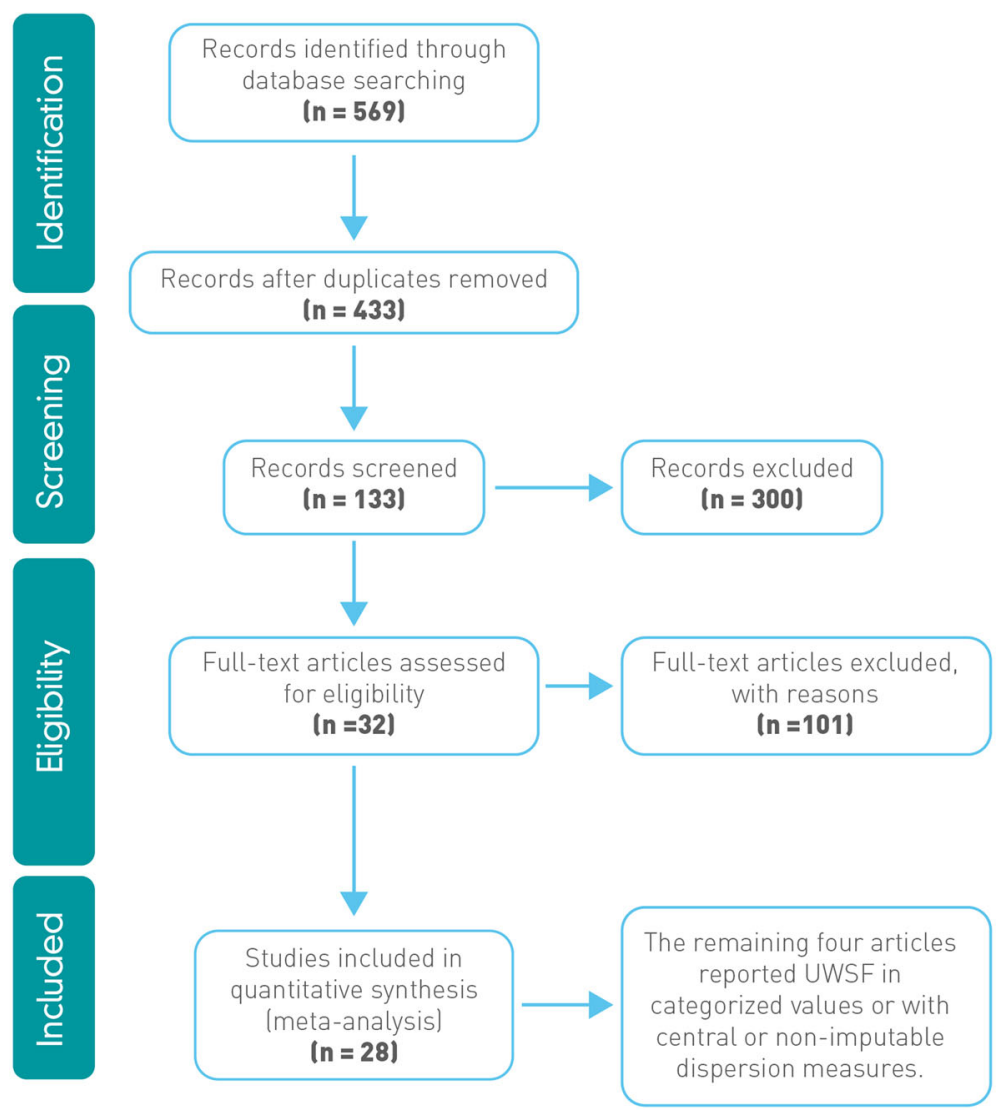

Fig. 1 PRISMA Flow-Diagram of article selection

$53.2 \%$ (1734) were controls. The age range of cases was 39 to 63 years old while the age range was 24 to 69 for controls. The female sex was the most frequent in both groups. With respect to patients with SS, 66\% (1010) had pSS, around 25.3\% (386) had SS, and 8.6\% (132) suffered from polyautoimmunity. Furthermore, patients with non-SS sicca came to 54.5\% (946), and healthy people were $45.5 \%$ (788) of the group of controls. In total, 28 articles were meta-analyzed to evaluate the differences in UWSF between patients with SS and controls (healthy subjects and patients with non-SS sicca). The UWSF in the remaining four articles could not be analyzed because the authors did not report absolute values. The total number of people in these 28 articles was 2759 patients and of these, $49.1 \%$ (1356) were cases. Of these, 63.8\% (866) had pSS, 26.5\% (359) had SS, and 9.7\% (131) had polyautoimmunity. Around 93\% (725) were female. Of the total, $50.9 \%$ (1403) were controls, and of the controls, 43.8\% (615) had non-SS sicca symptoms and 56.2\% (788) were healthy subjects. Female sex was also predominant and accounted for about 83.74\% (567).

Of the studies included in the meta-analysis, 13 were based on standardized methods of which the most widely used is that of Navazesh et al. [25], followed by
Vitali et al. [26], and Sreebny et al. [27]. The method used by Navazesh et al. [25], requires fasting, no smoking, no chewing gum, nor having any oral cavity procedures done for at least $1 \mathrm{~h}$ before the exam. It also requires $5 \mathrm{~min}$ of rest prior to the test during which orofacial movements must be minimized. Then, residual saliva must be swallowed before starting the procedure, and saliva must be expelled every minute for a period of 15 min during it.

\section{Meta-analysis results}

The pooled analysis demonstrated a lower UWSF in patients with SS [Mean difference (MD) $-0.18 \mathrm{ml} / \mathrm{min}$; 95\% $\mathrm{CI},-0.24$ to -0.13 ; $\mathrm{chi}^{2}-P$-value $\left.<0.00001\right]$ compared to controls (healthy subjects and patients with non-SS sicca) under a random-effects model. The $\mathrm{I}^{2}$ statistic, which estimates the total variability in the effect size, was calculated to be $97 \%$ (Fig. 2) and could be attributed to heterogeneity among the true effects.

A subgroup analysis (heterogeneity of $98 \%$ ) of patients with pSS reported that they had a lower UWSF compared to controls (healthy subjects and patients with non-SS sicca) (MD - 0.24 $\mathrm{ml} / \mathrm{min}$; 95\% CI, -0.32 to -0.16 ; $\mathrm{chi}^{2}$ $P$-Value $<0.00001)$. The comparison of pSS versus non-SS 
Table 2 Reasons for excluding the discarded articles

\begin{tabular}{|c|c|}
\hline Authors & Reason \\
\hline T. A Alfaya et al. & A case report \\
\hline S. Furness et al. & A narrative review \\
\hline S. Nusair, et al. & A literature Review \\
\hline D. Guellec et al. & A systematic review \\
\hline L. J Dawson et al. & \multirow{10}{*}{ All patients had SS } \\
\hline K. Haldorsen et al. & \\
\hline A. $\mathrm{K}$ Johansson et al. & \\
\hline D. Zoukhri et al. & \\
\hline N. L Rhodus et al. & \\
\hline Atkinson JC, et al. & \\
\hline Lundström IM, et al & \\
\hline Haga, $\mathrm{HJ}$, et al. & \\
\hline Fei YY, et al. & \\
\hline A. M. Al-Hamad et al. & \\
\hline K. Marton et al. & $\begin{array}{l}\text { All the patients had sicca symptoms, but no confirmed diagnosis of } \\
\text { SS }\end{array}$ \\
\hline J. M Meijer et al. & Clinical trial with rituximab in patients with pSS \\
\hline T. E Daniels et al. & \multirow{4}{*}{ Controls not included } \\
\hline Kojima, I et al. & \\
\hline Koh, JH et al. & \\
\hline Liu, $X$ et al. & \\
\hline J. Y Kang et al. & $\begin{array}{l}\text { Correlations between scintigraphic parameters and whole salivary } \\
\text { flow rate mentioned }\end{array}$ \\
\hline T. Mandl et al. & Data difficult to obtain. UWSF values are categorized \\
\hline A. Ardita et al. & $\begin{array}{l}\text { Included only patients with SS and another autoimmune disease. } \\
\text { UWSF VNM }\end{array}$ \\
\hline I.Castro et al. & Inclusion criteria not fulfilled \\
\hline M. R Hillen et al. & It is a letter to the editor. UWSF VNM \\
\hline $\begin{array}{l}\text { C. Manterola Delgado } \\
\text { et al. }\end{array}$ & It is a study about esophageal motility. UWSF VNM \\
\hline C. Vitali et al. & It is hard to obtain the data \\
\hline K. Ayar et al. & It is not clear which patients with celiac disease had SS \\
\hline M. T Brennan et al. & $\begin{array}{l}\text { Measure of saliva production only reported by submandibular and } \\
\text { parotid gland }\end{array}$ \\
\hline \multicolumn{2}{|l|}{ H. J. Haga et al. } \\
\hline H. F Oliveira et al. & No healthy controls or patients with non-SS sicca \\
\hline \multicolumn{2}{|l|}{$\begin{array}{l}\text { J. P Aitken-Saavedra } \\
\text { et al. }\end{array}$} \\
\hline S. Gotoh et al. & Only measure of saliva production by labial gland reported \\
\hline Y. J Lee et al. & Other autoimmune non-SS diseases included \\
\hline H. Asashima et al. & Patients with primary and polyautoimmunity compared \\
\hline H. Ben-Aryeh et al. & $\begin{array}{c}\text { Patients with sicca symptoms compared, but the SS group of } \\
\text { patients not reported }\end{array}$ \\
\hline H. Flink et al. & Patients with SS not included \\
\hline Hernández $\mathrm{C}$, et al. & Saliva is measured in $\mathrm{mm}$ with a filter paper. \\
\hline E. M Hay et al. & The patients did not have SS diagnosis \\
\hline A.M Lindvall et al. & They did not state how they diagnosed SS \\
\hline $\begin{array}{l}\text { E. Benedek -spät et } \\
\text { al. }\end{array}$ & $\begin{array}{l}\text { They report only a measurement of saliva production by parotid } \\
\text { gland }\end{array}$ \\
\hline K. Márton et al. & $\begin{array}{l}\begin{array}{l}\text { UWSF in patients with dental prostheses reported. No SS subjects } \\
\text { mentioned }\end{array}\end{array}$ \\
\hline N. L. Rhodus et al. & $\begin{array}{l}\text { UWSF of patients with SS vs sicca symptoms not distinguished. } \\
\text { Values of entire population with xerostomia mentioned }\end{array}$ \\
\hline A. Bookman et al. & \\
\hline C. N Carvalho et al. & UWSF values are categorized \\
\hline S. Retamozo et al. & \\
\hline
\end{tabular}

sicca disclosed a difference in the UWSF (MD-0.10 ml/ min; $95 \% \mathrm{CI},-0.13$ to -0.06 ; $\mathrm{chi}^{2}-P$-value $<0.00001$ with a heterogeneity of $82 \%$ ). As for the subgroup analysis (heterogeneity of 99\%) of patients with pSS versus healthy people, a difference in UWSF was observed (MD-0.43 ml/ min; $95 \%$ CI -0.49 to -0.27 ; chi $^{2}-P$-value $<0.00001$ ). In a subgroup analysis (heterogeneity of $97 \%$ ) by type of study design, the results were different but consistent with the
Table 2 Reasons for excluding the discarded articles (Continued)

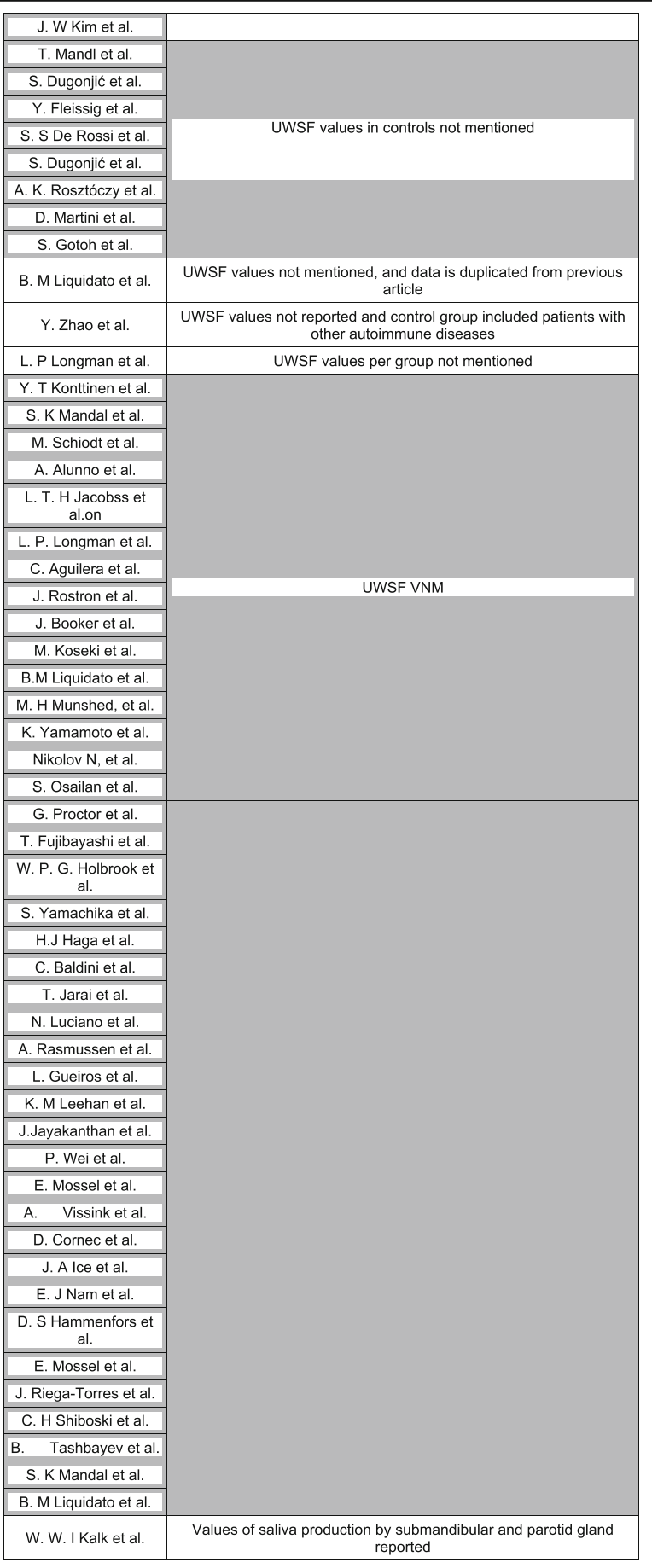

UWSF Unstimulated Whole Salivary Flow, pSS Primary Sjögren's Syndrome, SS Sjögren's Syndrome, VNM Values not mentioned

pooled results from all subgroups with the exception of the cross-sectional study group in which there were no significant differences (Fig. 3).

No statistically significant difference was found (MD$0.06 \mathrm{ml} / \mathrm{min} ; 95 \% \mathrm{CI}-0.14$ a $0.01 ; \mathrm{I}^{2}$ 93\%, chi2-s-value 
Table 3 Main results of the studies included in the meta-analysis

\begin{tabular}{|c|c|c|c|c|c|c|c|c|c|}
\hline & Study & Year & Cases & Controls & $\begin{array}{l}\text { Age (Years) in cases } \\
\text { (Mean } \pm \text { SD) }\end{array}$ & $\begin{array}{l}\text { Age (Years) in } \\
\text { controls }\end{array}$ & $\begin{array}{l}\text { UWSF }(\mathrm{ml} / \mathrm{min} \text { ) in cases } \\
\text { (Mean SD) }\end{array}$ & $\begin{array}{l}\text { UWSF (ml/min) in } \\
\text { controls (Mean SD) }\end{array}$ & $\begin{array}{l}\text { Quality of } \\
\text { evidence }^{a}\end{array}$ \\
\hline 1 & A.M Nahir et al. & 1987 & 9 & 20 & NA & NA & $0,06 \pm 0,02$ & $0,25 \pm 0,1$ & $10 / 10$ \\
\hline 2 & F.N. Skopouli & 1989 & 81 & 188 & NA & NA & $0,094 \pm 0,1$ & $0,406 \pm 0,272$ & $\begin{array}{l}\text { Not Enough } \\
\text { Information }\end{array}$ \\
\hline 3 & T. Filho & 1993 & 41 & 193 & NA & NA & $1,18 \pm 0,99$ & $2,47 \pm 0,99$ & $\begin{array}{l}\text { Not Enough } \\
\text { Information }\end{array}$ \\
\hline 4 & $\begin{array}{l}\text { U. Hakansson } \\
\text { et al. }\end{array}$ & 1994 & 17 & 42 & $63(53-72)^{b}$ & $69(57-72)^{\mathrm{b}}$ & $0,025 \pm 0,042$ & $0,14 \pm 0,16$ & $10 / 10$ \\
\hline 5 & N. Rhodus et al. & 1997 & 18 & 9 & $54,5(37-74)^{c}$ & $56,1(38-74)^{c}$ & $0,0216 \pm 0,004$ & 0,431 SE 0,092 & $9 / 10$ \\
\hline 6 & N.L Rhodus et al. & 1998 & 10 & 10 & $57,2(37-74)^{b}$ & $57,4(41-80)^{b}$ & $0,0094 \pm 0,004$ & 0,096 SE 0,16 & $10 / 10$ \\
\hline 7 & S.L Wang et al. & 1998 & 30 & 23 & $39(28-62)^{b}$ & $42(29-69)^{b}$ & $0,070 \pm 0,089$ & $0,330 \pm 0,188$ & $10 / 10$ \\
\hline 8 & $\begin{array}{l}\text { A.M Pedersen } \\
\text { et al. }\end{array}$ & 1999 & 16 & 27 & $61,5(40-82)^{c}$ & $50(39-70)^{c}$ & $0,05(0-0,1)$ & $0.31(0,14-0,90)$ & $10 / 10$ \\
\hline 9 & A. Vissink et al. & 2003 & 57 & 36 & $53 \pm 14$ & $48 \pm 12$ & $0,05 \pm 0.08$ & $0.23 \pm 0.15$ & $10 / 10$ \\
\hline 10 & A. Negoro et al. & 2004 & 31 & 47 & $55,2 \pm 13,1$ & $32,3 \pm 5,9$ & $0,07 \pm 0,07$ & $0,282 \pm 0,22$ & $10 / 10$ \\
\hline 11 & K. Márton et al. & 2006 & 49 & 43 & $55 \pm 11$ & NA & $0,12 \pm 0,13$ & $0,37 \pm 0,24$ & $9 / 10$ \\
\hline 12 & $\begin{array}{l}\text { I Van Den Berg } \\
\text { et al }\end{array}$ & 2009 & 62 & 114 & NA & NA & $0,08 \pm 0,13$ & $0,22 \pm 0,18$ & $11 / 11$ \\
\hline 13 & A. Bookman et al. & 2010 & 265 & 70 & NA & NA & $0,046 \pm 0,086$ & $0,093 \pm 0,093$ & $8 / 8$ \\
\hline 14 & T. Kitagawa et al. & 2011 & 45 & 54 & $60,9 \pm 9,9$ & $67,1 \pm 11,3$ & $0,015 \pm 0,026$ & $0,071 \pm 0.058$ & $8 / 8$ \\
\hline 15 & E. H. Kang et al. & 2011 & 30 & 55 & $49,9 \pm 9$ & $51,5 \pm 10$ & $0,06 \pm 0,05$ & $0,15 \pm 0,12$ & $10 / 10$ \\
\hline 16 & C. Baldini et al. & 2011 & 55 & 10 & $52,4 \pm 10,5$ & $56 \pm 10,7$ & $1,05 \pm 0,77$ & $1,02 \pm 0,78$ & $10 / 10$ \\
\hline 17 & B. Busamia et al. & 2012 & 32 & 41 & 53 & NA & $0,22 \pm 0,03$ & $0,36 \pm 0,05$ & $8 / 8$ \\
\hline 18 & $\begin{array}{l}\text { M. A. D. Anjos } \\
\text { Corvo et al }\end{array}$ & 2012 & 19 & 12 & 60 & 44 & $0,127 \pm 0,106$ & $0,402 \pm 0,16$ & $9 / 10$ \\
\hline 19 & G. Mumcu et al. & 2013 & 14 & 10 & $51,3 \pm 5,03$ & $43,4 \pm 9,5$ & $0,04 \pm 0,01$ & $1,73 \pm 1,3$ & $9 / 10$ \\
\hline 20 & N. Berman et al. & 2014 & 104 & 121 & $53,8 \pm 13,7$ & $51,9 \pm 13,2$ & $0,46 \pm 0,24$ & $0,85 \pm 0,3$ & $9 / 10$ \\
\hline 21 & $\begin{array}{l}\text { M.A.D Anjos } \\
\text { Corvo et al }\end{array}$ & 2014 & 12 & 11 & $56,25 \pm 8,6$ & $56,1 \pm 12,7$ & $0,16 \pm 0,162$ & $0,26 \pm 0,144$ & $10 / 10$ \\
\hline 22 & K. Ohyama et al. & 2015 & 90 & 36 & $61,9 \pm 9,8$ & $42,4 \pm 15,1$ & $0,5 \pm 0,1$ & $0,25 \pm 0,15$ & $10 / 10$ \\
\hline 23 & C. Baldini et al. & 2015 & 50 & 57 & $47 \pm 13$ & $53 \pm 12$ & $0,153 \pm 0,173$ & $0,32 \pm 0,226$ & $8 / 8$ \\
\hline 24 & $\begin{array}{l}\text { N.M.A Chaudhury } \\
\text { et al. }\end{array}$ & 2015 & 24 & 30 & 55,25 SE 3,29 & 56,53 SE 3,43 & $0,14 \pm 0,03$ & $0,42 \pm 0,05$ & $10 / 10$ \\
\hline 25 & E.C Barbosa et al. & 2016 & 10 & 7 & NA & NA & 0,18 & 0,67 & $10 / 10$ \\
\hline 26 & S. Rusthen et al. & 2017 & 31 & 33 & $52 \pm 12,4$ & $50,1 \pm 12,7$ & $0,08 \pm 0,07$ & $0,29 \pm 0,17$ & $9 / 10$ \\
\hline 27 & $\begin{array}{l}\text { Fernández- } \\
\text { Martínez et al. }\end{array}$ & 2018 & 60 & 60 & $55,5 \pm 14,3$ & $55,7 \pm 8,1$ & $0,016 \pm 0,004$ & $0,12 \pm 0,7$ & $10 / 10$ \\
\hline 28 & K-A Lee et al. & 2018 & 94 & 44 & $55,6 \pm 12,2$ & $59,2 \pm 11,8$ & $0,146 \pm 0,15$ & $0,226 \pm 0,23$ & $10 / 11$ \\
\hline
\end{tabular}

Most of values are expressed on mean and standard deviation or median and interquartile rank. All the values were converted to $\mathrm{ml} / \mathrm{min}$ units. To the articles which report UWSF in subgroups, a mean was calculated

UWSF Unstimulated Whole Salivary Flow, NA Not available, SE Standard Error

a Joanna Briggs Checklist., ${ }^{\mathrm{b}}$ Mean (Range), ${ }^{\mathrm{C}}$ Median (Interquartile range)

$<0.11$ with a heterogeneity of 93\%) when UWSF in patients with pSS was compared to those with polyautoimmunity.

As for publication bias, visual inspection of the funnel plot shows asymmetry (Fig. 4), and that was confirmed by an Egger's regression test $(P=0.0001)$.

\section{Discussion}

Here, for the first time (to our knowledge), a metaanalysis shows that the unstimulated whole salivary flow rate is lower in patients with Sjögren's syndrome compared to controls (healthy and non-SS sicca patients). A mean difference value of $-0.18 \mathrm{ml} / \mathrm{min}(95 \%$ CI, -0.24 to- $0.13, P$-value $<0.00001)$ is disclosed.

The above result is important given the role that saliva plays in oral health. For example, saliva provides the teeth with protection and lubrication and fosters their remineralization. It also cooperates with the transportation of digestive enzymes. It has antimicrobial properties and plays a part in chewing and swallowing. It is estimated that the saliva production rate is 0.5 to $1.5 \mathrm{Lt} /$ day in healthy adults $[7,28]$. The glands responsible for 


\begin{tabular}{|c|c|c|c|c|c|c|c|c|c|c|}
\hline Study or Subgroup & Mean & SS & Total & \multicolumn{3}{|c|}{ Controls } & \multicolumn{2}{|c|}{$\begin{array}{c}\text { Mean Difference } \\
\text { Weight }\end{array}$} & \multicolumn{2}{|c|}{$\begin{array}{c}\text { Mean Difference } \\
\mathrm{N}, \text { Random, } 95 \% \mathrm{Cl}\end{array}$} \\
\hline A. C. Bookman et al. 2010 & 0.046 & 0.086 & 265 & 0.093 & 0.093 & 70 & $4.2 \%$ & $-0.05[-0.07,-0.02]$ & & \\
\hline A. Negoro et al. 2004 & 0.07 & 0.07 & 31 & 0.31 & 0.22 & 47 & $4.0 \%$ & $-0.24[-0.31,-0.17]$ & - & \\
\hline A.K Vissink et al. 2003 & 0.07 & 0.12 & 57 & 0.23 & 0.15 & 36 & $4.1 \%$ & $-0.16[-0.22,-0.10]$ & - & \\
\hline A.M Nahir et al. 1987 & 0.06 & 0.02 & 9 & 0.25 & 0.1 & 20 & $4.1 \%$ & $-0.19[-0.24,-0.14]$ & - & \\
\hline A.M.R Pedersen et al.1999 & 0.05 & 0.025 & 16 & 0.26 & 0.13 & 27 & $4.1 \%$ & $-0.21[-0.26,-0.16]$ & - & \\
\hline B. G. Busamia et al. 2012 & 0.27 & 0.03 & 32 & 0.07 & 0.076 & 41 & $4.2 \%$ & $0.20[0.17,0.23]$ & & - \\
\hline C Baldini. et al 2011 & 1.054 & 0.67 & 55 & 1.02 & 0.78 & 10 & $0.9 \%$ & $0.03[-0.48,0.55]$ & & \\
\hline C Baldini. et al2015 & 0.153 & 0.173 & 50 & 0.32 & 0.226 & 57 & $3.9 \%$ & $-0.17[-0.24,-0.09]$ & $\rightarrow$ & \\
\hline E. H. Kang et al. 2011 & 0.06 & 0.05 & 30 & 0.2 & 0.13 & 55 & $4.2 \%$ & $-0.14[-0.18,-0.10]$ & - & \\
\hline E.C Barbosa et al.2016 & 0.1 & 0.05 & 10 & 0.292 & 0.146 & 7 & $3.6 \%$ & $-0.19[-0.30,-0.08]$ & & \\
\hline F.N. Skopouli1989 & 0.094 & 0.1 & 81 & 0.406 & 0.272 & 188 & $4.1 \%$ & $-0.31[-0.36,-0.27]$ & - & \\
\hline Fernández-Martinez et al.2018 & 0.016 & 0.008 & 60 & 0.12 & 0.06 & 60 & $4.3 \%$ & $-0.10[-0.12,-0.09]$ & - & \\
\hline G. Mumcu et al.2013 & 0.04 & 0.02 & 14 & 1.73 & 0.865 & 10 & $0.8 \%$ & $-1.69[-2.23,-1.15]$ & 1 & \\
\hline I Van Den Berg et al. 2009 & 0.08 & 0.13 & 62 & 0.167 & 0.165 & 114 & $4.2 \%$ & $-0.09[-0.13,-0.04]$ & $\rightarrow$ & \\
\hline KOhyama et al. 2015 & 0.5 & 0.25 & 90 & 0.25 & 0.125 & 36 & $4.0 \%$ & $0.25[0.18,0.32]$ & & $\rightarrow$ \\
\hline K. A. L. Lee et al. 2017 & 0.146 & 0.15 & 94 & 0.226 & 0.23 & 44 & $4.0 \%$ & $-0.08[-0.15,-0.01]$ & & \\
\hline K. Márton K. et al. 2006 & 0.12 & 0.13 & 49 & 0.37 & 0.24 & 43 & $3.9 \%$ & $-0.25[-0.33,-0.17]$ & $\rightarrow$ & \\
\hline M. A. d. A. Corvo et al. 2012 & 0.127 & 0.106 & 19 & 0.402 & 0.201 & 12 & $3.5 \%$ & $-0.28[-0.40,-0.15]$ & & \\
\hline M.A.D Anjos Corvo et al.2014 & 0.16 & 0.162 & 12 & 0.26 & 0.144 & 11 & $3.5 \%$ & $-0.10[-0.23,0.03]$ & & \\
\hline N Berman et al 2014 & 0.46 & 0.23 & 104 & 0.85 & 0.425 & 121 & $3.8 \%$ & $-0.39[-0.48,-0.30]$ & $\rightarrow$ & \\
\hline N.L Rhodus et al.1998 & 0.0094 & 0.012 & 10 & 0.096 & 0.5 & 10 & $1.8 \%$ & $-0.09[-0.40,0.22]$ & & \\
\hline N.L Rhodus et al.1997 & 0.0233 & 0.015 & 18 & 0.43 & 0.276 & 9 & $2.9 \%$ & $-0.41[-0.59,-0.23]$ & - & \\
\hline N.M.A Chaudhury et al. 2015 & 0.14 & 0.03 & 24 & 0.42 & 0.27 & 30 & $3.8 \%$ & $-0.28[-0.38,-0.18]$ & & \\
\hline S. Rusthen et al.201? & 0.08 & 0.07 & 31 & 0.29 & 0.17 & 33 & $4.0 \%$ & $-0.21[-0.27,-0.15]$ & & \\
\hline S.L Wang et al.1998 & 0.07 & 0.089 & 30 & 0.33 & 0.188 & 23 & $3.9 \%$ & $-0.26[-0.34,-0.18]$ & - & \\
\hline T Kitagawa et al.2011 & 0.015 & 0.02 & 45 & 0.071 & 0.058 & 54 & $4.2 \%$ & $-0.06[-0.07,-0.04]$ & - & \\
\hline T. Filho 1993 & 1.18 & 0.99 & 41 & 2.47 & 0.99 & 193 & $1.7 \%$ & $-1.29[-1.62,-0.96]$ & $\leftarrow$ & \\
\hline U. J. Hakansson et al. 1994 & 0.025 & 0.042 & 17 & 0.15 & 0.15 & 42 & $4.1 \%$ & $-0.13[-0.17,-0.08]$ & - & \\
\hline Total $(95 \% \mathrm{Cl})$ & & & 1356 & & & 1403 & $100.0 \%$ & $-0.18[-0.24,-0.13]$ & $\bullet$ & \\
\hline $\begin{array}{l}\text { Heterogeneity: } \mathrm{Tau}^{2}=0.02 ; \mathrm{Ch} \\
\text { Test for overall effect: } Z=6.53\end{array}$ & 000 & & & & & & & & -0.5 & iontro \\
\hline
\end{tabular}

Fig. 2 Forest plot (random-effects model Mean Differences) of the unstimulated whole salivary flow rate in patients with Sjögren's Syndrome compared to controls (healthy subjects and patients with sicca non-SS). This forest plot summarizes the results of studies evaluating the unstimulated whole salivary flow rate in patients with Sicca symptoms (SS vs controls). The numbers on the x-axis measure mean difference. The small green boxes represent the point estimate of the effect size and sample size of each study. The black lines on either side of the box represent a 95\% confidence interval. The solid vertical line represents a mean difference of 0 or no effect. The overall pooled mean difference and $95 \% \mathrm{Cl}$ is indicated by a diamond at the bottom. Names of the first author's studies are shown on the left. Cl: Confidence Interval; df: degree freedom; Chi2: chi-squared test; 12: Higgins heterogeneity test; SD: Standard deviation; SS: Sjögren's Syndrome

saliva production are the major salivary glands (parotid, sublingual, and submandibular) and account for $90 \%$ of it. The remaining $10 \%$ of saliva production is attributed to the minor salivary glands that are diffusely distributed in the oral mucosa $[7,29]$.

Diminished production of the salivary flow rate implies the hypo-function of salivary glands. Therefore, it is essential to find out what the main causes of the compromised flow rate are. The adverse effects of medication, therapeutic irradiation, and SS are common causes of decreased salivary flow. The ACR/EULAR criteria are used for the SS diagnosis. They include the UWSF rate, and if the salivary production is $\leq 0.1 \mathrm{ml} /$ min or $\leq 1.5 \mathrm{ml}$ in $15 \mathrm{~min}$, the criteria assign one point to the final calculation. Unfortunately, in the majority of the cases, this test is only applied when the patient does not have dry eye by objective measures (Schirmer test or ocular staining score) [30]. In general terms, there is a consensus in the literature on the UWSF cutoff point that demonstrates glandular hypofunction when its value is $\leq 0.1 \mathrm{ml} / \mathrm{min}$. However, it has been suggested that values between 0.1 to $0.2 \mathrm{ml} / \mathrm{min}$ could be the lower threshold, and that values $>0.2 \mathrm{ml} / \mathrm{min}$ are found in healthy people [31].

The value of $\leq 0.1 \mathrm{ml} / \mathrm{min}$ includes all the people with dry eye/mouth symptoms resulting from causes that cannot be differentiated from SS. Traditionally, this cutoff point of UWSF is used for the SS diagnosis. However, the origin of this value is not clear in the literature review (Table 4). In 1975, Daniels et al. said that there were no established specific criteria for determining the presence of the oral component of SS, but since then, the abovementioned cut-off point has been used in different sets of criteria for patients with suspected SS with no solid scientific support [15]. Thus, this Systematic Literature Review (SLR) and meta-analysis were developed to evaluate the difference using an objective measure. In the present study, the difference in the value of the UWSF for controls and the one for SS was found to be $-0.18 \mathrm{ml} / \mathrm{min}$. Note that out of the 1403 controls included, a considerable group were healthy subjects $(n=$ 788). That is why, when a subgroup analysis is done to evaluate the difference in UWSF between pSS and healthy people, it shows a higher than expected difference, $-0.43 \mathrm{ml} / \mathrm{min}$.

Furthermore, the controls with non-SS sicca in the present results include subjects with sialosis, fibromyalgia, radiotherapy, burn mouth syndrome, diabetes, arterial hypertension, sodium retention syndrome, dyslipidemia, positive serology for hepatitis C, hyperthyroidism, hypothyroidism, osteoarthritis, and neoplasia. A minor difference in the saliva production $(-0.10 \mathrm{ml} /$ min) was found in the subgroup analysis of patients with pSS and non-SS sicca as was expected. In a 2016 systematic literature review that evaluated the level of xerostomia, hypo-salivation, and salivary flow rate in patients with diabetes, the UWSF rate was found to be 0.16 to $0.55 \mathrm{ml} / \mathrm{min}$ in the group of patients and 0.26 to 0.75 


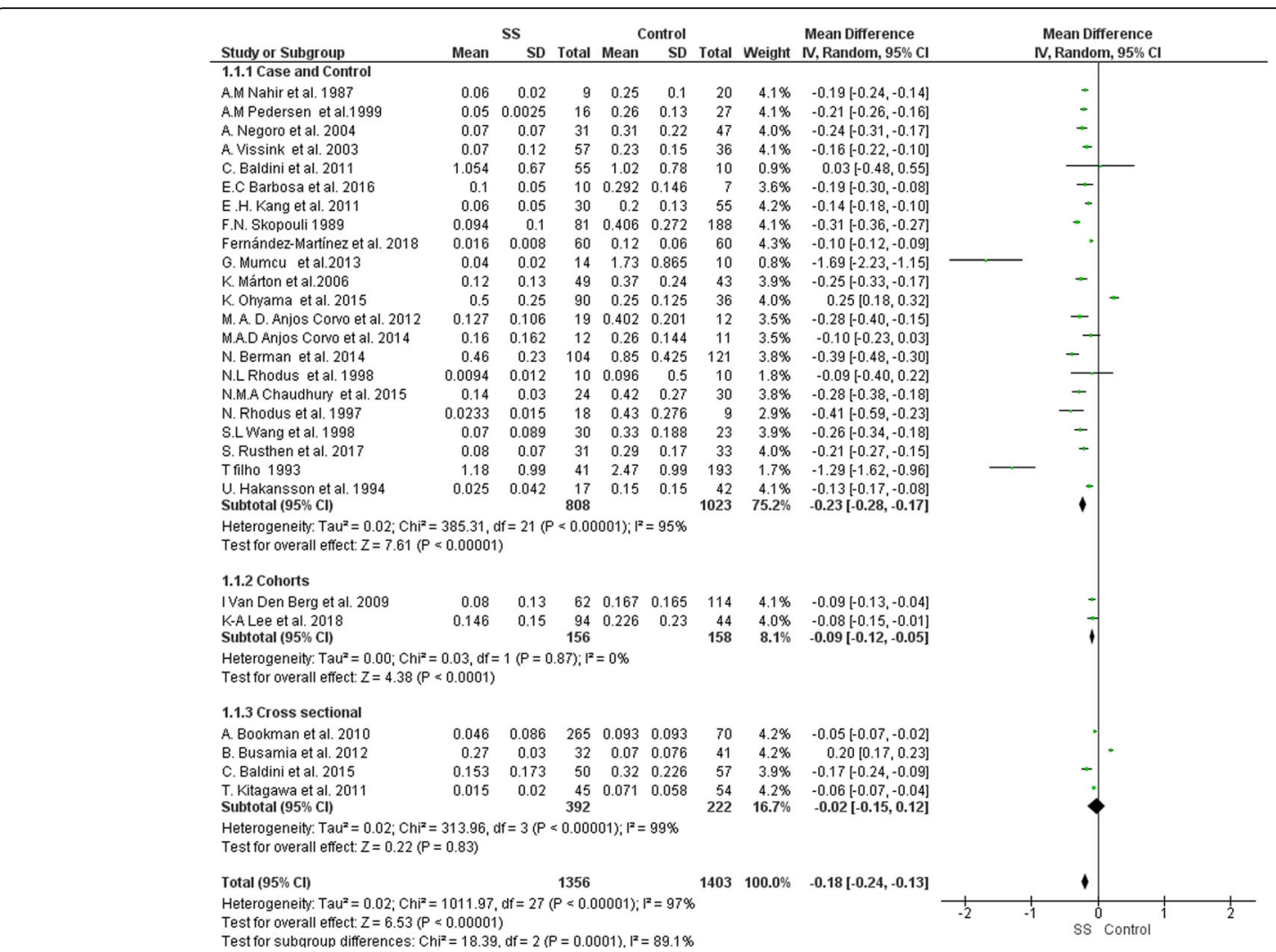

Fig. 3 Forest plot (random-effects model Mean Differences) of the unstimulated whole salivary flow rate in patients with Sjögren's Syndrome compared to controls (healthy subjects and patients with sicca non-SS) by study design type. Names of the first author's studies are shown on the left. Cl: Confidence Interval; df: degree freedom; Chi2: chi-squared test; I2: Higgins heterogeneity test; SD: Standard deviation; SS: Sjögren's Syndrome

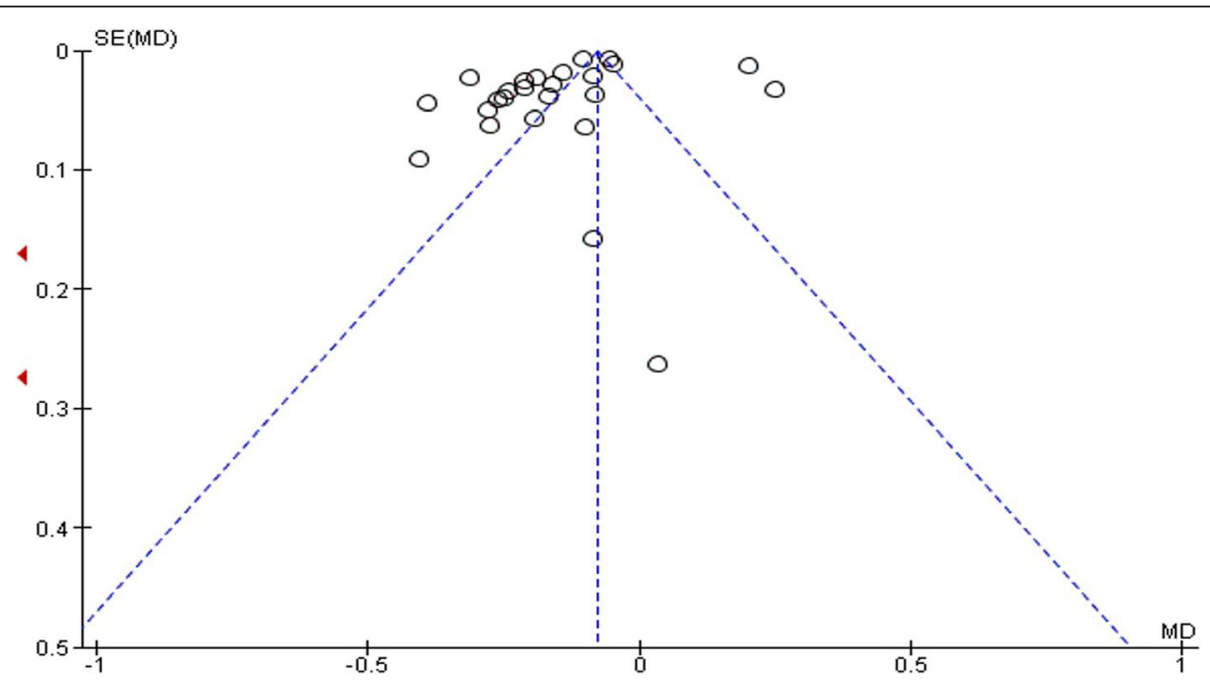

Fig. 4 Funnel plot of published studies evaluating the unstimulated whole salivary flow rate in patients with Sjögren's Syndrome compared to controls (healthy subjects and patients with non-SS sicca). It shows an important publication bias with an asymmetric article distribution. A funnel plot of standard error versus the unstimulated whole salivary flow difference in means is shown. Visual inspection of the funnel plot (scatter diagram) shows asymmetric article distribution confirmed by an Egger's regression test ( $P=0.0001)$. MD: mean difference; SE: Standard error 
Table 4 Historical criteria background for saliva production in Sjögren's syndrome diagnosis

\begin{tabular}{|c|c|c|c|}
\hline Author & Year & Objective dry mouth evaluation included for diagnosis. & Value \\
\hline $\begin{array}{l}\text { Daniels } \\
\text { et al. }\end{array}$ & 1975 & $\begin{array}{l}\text { There are no established objective criteria for determining the presence of the oral } \\
\text { component of SS. }\end{array}$ & NA \\
\hline $\begin{array}{l}\text { Manthorpe } \\
\text { et al. }\end{array}$ & $\begin{array}{l}1975- \\
1976\end{array}$ & No & NA \\
\hline $\begin{array}{l}\text { Skopoul } \\
\text { et al. }\end{array}$ & 1986 & No, they mention subjective xerostomia and stimulated modified whole sialometry & NA \\
\hline Fox et al. & 1986 & No & $\begin{array}{l}\text { Just mention decreased basal } \\
\text { and stimulated salivary flow } \\
\text { rate }\end{array}$ \\
\hline Vitali et al. & 1993 & $\begin{array}{l}\text { Objective evidence of salivary gland involvement determined based on a positive result from } \\
\text { at least } 1 \text { of the following } 3 \text { tests: Salivary scintigraphy, parotid sialography, USF. }\end{array}$ & USF $\leq 1,5 \mathrm{ml} / 15 \mathrm{~min}$ \\
\hline $\begin{array}{l}\text { Fujibayashi } \\
\text { et al. }\end{array}$ & 1999 & Optional in an item, gum or Saxon test & NA \\
\hline Vitali et al. & 2002 & Yes & UWSF $\leq 1,5 \mathrm{ml} / 15 \mathrm{~min}$ \\
\hline $\begin{array}{l}\text { Fujibayashi } \\
\text { et al. }\end{array}$ & 2004 & Yes & Flow rate $\leq 10 \mathrm{ml} / 10 \mathrm{~min}$ \\
\hline $\begin{array}{l}\text { Shiboski } \\
\text { et al. }\end{array}$ & 2012 & No & NA \\
\hline $\begin{array}{l}\text { Shiboski } \\
\text { et al. }\end{array}$ & 2016 & Yes & UWSF $\leq 0,1 \mathrm{ml} / \mathrm{min}$ \\
\hline
\end{tabular}

NA Not available, USF Unstimulated Salivary Flow, UWSF Unstimulated Whole Salivary Flow

$\mathrm{ml} / \mathrm{min}$ in the control group. This is similar to the present results even though this population corresponds to non-autoimmune diabetes (Type 2) [32].

Another meta-analysis from 2018 involved subjects with autoimmune thyroid diseases and oral lichen planus. SS was eliminated from the study, and it included 130 patients in the end. The authors analyzed UWSF values and found a diminished production of UWSF in the group of patients compared to controls $(-1.09 ;-1$. 49, $-0.7 ; P$-value <0.001) [10]. It reveals the lack of studies that include patients with other autoimmune diseases. However, it shows evidence of a greater difference in the mean value of UWSF in cases versus controls in comparison to our meta-analysis of values of UWSF of patients with SS versus controls.

The clinical usefulness and practical implications of the present results show that cases have $-0.18 \mathrm{ml} / \mathrm{min}$ of unstimulated salivary flow compared to controls. This implies that in $1 \mathrm{~h}$, patients present a saliva production of $11 \mathrm{ml}$ less than controls, directly impacting previously mentioned basic physiological functions. The present meta-analysis results could be involved in future studies to define new UWSF cut-off points that better discriminate between patients with SS vs. sicca non-SS by analyzing sensitivity, specificity, and through ROC curves.

In addition, this could guide new research focused on modifying the pre-stablished cut-off point for making treatment decisions. In fact, the recent EULAR recommendations for the management of Sjögren's syndrome [8] suggested a first evaluation considering the UWSF measurement, and if the value is $<0.1 \mathrm{ml} / \mathrm{min}$, they proposed to classifying the patients according to SWSF values $\quad(>0.7 \mathrm{ml} / \mathrm{min}$ : normal $/ \mathrm{mild}, \quad 0.7-0.1 \mathrm{ml} / \mathrm{min}$ : moderate and $<0.1 \mathrm{ml} / \mathrm{min}$ : severe dysfunction). If SWSF values showed severe dysfunction, saliva substitution should be considered the preferred therapeutic approach to alleviate symptoms. This would be needed given that in patients with no residual glandular function (severe glandular dysfunction), salivary glands cannot be stimulated, either by pharmacological or non-pharmacological interventions. The present meta-analysis results might guide new discussions regarding practical implications with respect to not only the diagnostic process, but also, treatment decisions given the limitations on developing the SWSF measurement. This is a complicated test in daily practice and not always available in all clinical settings as was mentioned by the EULAR panel in their recommendations. It might be feasible to discuss avoiding the SWSF test and using the UWSF instead given the objective saliva production measurement based on the present results.

The limitations of the present study include its heterogeneity through the $\mathrm{I}^{2}$ test and the publication bias as evinced in the funnel plot due to the fact that it had a preponderance of studies with a small sample size $(95 \%$ smaller than a $n=100)$. Additionally, there are variations in the saliva collection technique and the sampling time in the different articles. Therefore, the results have to be taken with caution. Nonetheless, this exercise supports the need to unify criteria for clinical evaluation, monitor patients with sicca symptoms, and set up epidemiological studies with larger sample sizes and greater homogeneity in their comorbidities. 
Moreover, the study design included articles that were mostly cross-sectional and cohort studies with a three or four level of evidence. There were fewer articles that compared SS patients with diagnoses of other autoimmune diseases (polyautoimmunity) to pSS patients and, as a result, no difference was found. Therefore, this could be an important step for future research.

Unfortunately, the articles did not provide enough information to do a meta-regression. Furthermore, some of them were not clear with respect to whether or not the cases and controls were receiving pharmacological treatments or had comorbidities or other diseases that could have an influence on the values of the UWSF.

\section{Conclusion}

For the first time, the difference in the values of the UWSF rate in patients with SS compared to controls (non-SS sicca subjects and healthy people) was objectively demonstrated through a meta-analysis. The purpose behind this study is to challenge the different specialists in oral health and rheumatology regarding the importance of the use of UWSF, which has the same weight within the classification criteria [14] for SS as the Schirmer test or the ocular staining score test. This takes into account the fact that eye tests are done more frequently than the UWSF in real-life conditions in the context of SS diagnosis. The results of our research will make it possible to understand the objective assessment of cut-off points for UWSF in SS and in other causes of xerostomia.

\section{Acknowledgments}

We would like to recognize Cecile Dunn for her technical support concerning the English language and the Internal call for the improvement of English scientific manuscripts from the Fundación Universitaria de Ciencias de la Salud -FUCS.

\section{Authors' contributions \\ Dr. Adriana Rojas had full access to all the data in the study and takes responsibility for the integrity of the data and the accuracy of the data analysis. Concept and design: M. A Martínez-Ceballos, N Aguilera, JP Alzate- Granados, K. C Garzón-González, J. Cajamarca, A. Rojas-Villarraga. Acquisition, analysis or interpretation of data: M. A Martínez-Ceballos, N Aguilera, JP Alzate- Granados, K. C Garzón-González, J. Cajamarca, A. Rojas-Villarraga. Drafting of the manuscript: M. A Martínez-Ceballos, N Aguilera, JP Alzate- Granados, K. C Garzón-González, J. Cajamarca, A. Rojas-Villarraga. Critical revi- sión of the manuscript for important intellectual content: M. A Martínez- Ceballos, N Aguilera, JP Alzate- Granados, K. C Garzón-González, J. Cajamarca, A. Rojas-Villarraga. Statistical analysis: A Rojas-Villarraga, JP Alzate- Granados, M. Martínez-Ceballos. Administrative, technical, or material support: M. A Mar- tínez-Ceballos, N Aguilera, JP Alzate- Granados, K. C Garzón-González, J. Caja- marca, A. Rojas-Villarraga. Supervision: A Rojas-Villarraga, JP Alzate-Granados. The author(s) read and approved the final manuscript.}

\section{Funding}

None.

\section{Availability of data and materials}

The datasets used and/or analyzed during the current systematic literature review and meta-analysis are available under request.

\section{Ethics approval and consent to participate}

The present manuscript is a systematic literature review and metanalysis with data collection from the literature in the public domain, without direct collection data involving patients nor animals. Therefore, there is no appraisal by ethics committee.

\section{Consent for publication}

Not applicable.

\section{Competing interests}

The authors declare that the do not have competing interests.

\section{Author details \\ ${ }^{1}$ Research Division Fundación Universitaria de Ciencias de la Salud (FUCS), Bogotá, Colombia. ${ }^{2}$ Internal Medicine Department, Fundación Universitaria de Ciencias de la Salud (FUCS). Hospital San José, Bogotá, Colombia. ${ }^{3}$ Rheumatology Department, Fundación Universitaria de Ciencias de la Salud (FUCS), Bogotá, Colombia. ${ }^{4}$ Research Institute, Fundación Universitaria de Ciencias de la Salud (FUCS), Bogotá, Colombia.}

Received: 29 July 2020 Accepted: 22 December 2020

Published online: 03 February 2021

References

1. Rostron J, Rogers S, Longman L, Kaney S, Field EA. Health-related quality of life in patients with primary Sjögren's syndrome and xerostomia: a comparative study. Gerodontology. 2002;19(1):53-9.

2. Anaya JM, Rojas-Villarraga A, Mantilla RD, Arcos-Burgos M, SarmientoMonroy JC. Polyautoimmunity in Sjögren Syndrome. Rheum Dis Clin North Am. 2016:42:457-72 W.B. Saunders.

3. Mariette X, Criswell LA. Primary Sjögren's syndrome. N Engl J Med. 2018; 378(10):931-9.

4. Qin B, Wang J, Yang Z, Yang M, Ma N, Huang F, et al. Epidemiology of primary Sjögren's syndrome: a systematic review and meta-analysis. Ann Rheum Dis. 2015 Nov;74(11):1983-9.

5. Brito-Zerón P, Baldini C, Bootsma H, Bowman SJ, Jonsson R, Mariette X, et al. Sjögren Syndrome. Nat Rev. 2016;2:1-20.

6. Shiboski SC, Shiboski CH, Criswell LA, Baer AN, Challacombe S, Lanfranchi H, et al. American College of Rheumatology Classification Criteria for Sjögren's Syndrome: a data-driven, expert consensus approach in the SICCA cohort. Arthritis Care Res (Hoboken). 2012;64(4):475-87.

7. Navazesh M, Kumar SK. Measuring salivary flow Challenges and opportunities. J Am Dent Assoc. 2008;139:5S-40S.

8. Ramos-Casals M, Brito-Zerón P, Bombardieri S, Bootsma H, De Vita S, Dörner T, et al. EULAR recommendations for the management of Sjögren's syndrome with topical and systemic therapies. Ann Rheum Dis. 2020;79(1): 3-18.

9. Hoseini A, Mirzapour A, Bijani A, Shirzad A. Salivary flow rate and xerostomia in patients with type I and || diabetes mellitus. Electron Physician. 2017;9(9): 5244-9.

10. Moosavi M-S, Barati H. Salivary gland performance in autoimmune diseases: review and meta-analysi. Acta Clin Belg. 2020;75(1):19-25. https://doi.org/10. 1080/17843286.2018.1540164. Epub 2018 Oct 30.

11. Naik M, Vaishnavee V. Qualitative and quantitative salivary changes and subjective oral dryness among patients with thyroid dysfunction. Indian 」 Dent Res. 2018;29(1):16.

12. Knaś M, Zalewska A, Waszkiewicz N, Szulimowska J, Dziezcioł J, Sierakowski $S$, et al. Salivary: flow and proteins of the innate and adaptive immunity in the limited and diffused systemic sclerosis. J Oral Pathol Med. 2014;43(7): $521-9$.

13. Kobus A, Kierklo A, Zalewska A, Kuźmiuk A, Szajda SD, Ławicki S, et al. Unstimulated salivary flow, $\mathrm{pH}$, proteins and oral health in patients with juvenile idiopathic arthritis. BMC Oral Health. 2017;17(1):94.

14. Shiboski CH, Shiboski SC, Seror R, Criswell LA, Labetoulle M, Lietman TM, et al. 2016 American College of Rheumatology/European league against rheumatism classification criteria for primary Sjögren's syndrome a consensus and data-driven methodology involving three international patient cohorts. Ann Rheum Dis. 2017;76:9-16.

15. Daniels TE, Silverman S, Michalski J, Greenspan J, Path M, Sylvester R, et al. The oral component of Sjögren's syndrome. Oral Surgery, Oral Med Oral Pathol. 1975;39(6):875-88. 
16. Manthorpe R, Oxholm P, Prause JU, Schiodt M. The Copenhagen Criteria for Sjögren's syndrome. Scand J Rheumatol. 1986;61:19-21.

17. Skopouli FN, Drosos AA, Papaioannou T, Moutsopoulos HM. Preliminary diagnostic criteria for Sjögren's syndrome. Scand J Rheumatol. 1986; 15(Suppl. 61):22-5.

18. Fox Rl, Robinson CA, Curd JG, Kozin F, Howell F. Sjögren syndrome proposed criteria for classification. Arthritis Rheum. 1986;29(5):577-85.

19. Balestrieri G, Bencivelli W, Bernstein RM, Bjerrum KB, Braga S, Coll J, et al. Preliminary criteria for the classification of Sjogren' S Syndrome results of a prospective concerted action supported by the European Community. Arthritis Rheum. 1993;36(3):340-7.

20. Fujibayashi T, Sugai S, Miyasaka N, Hayashi Y, Tsubota K. Revised Japanese criteria for Sjögren's syndrome (1999): availability and validity. Mod Rheumatol. 2004;14(6):425-34.

21. Liberati A, Altman DG, Tetzlaff J, Mulrow C, Gøtzsche PC, loannidis JPA. The PRISMA statement for reporting systematic reviews and meta-analyses of studies that evaluate health care interventions: explanation and elaboration. J Clin Epidemiol. 2009;62:e1-34.

22. Vitali C, Bombardieri S, Jonsson R, Moutsopoulos HM, Alexander EL, Carsons $S E$, et al. Classification criteria for Sjögren's syndrome: a revised version of the European criteria proposed by the American-European Consensus Group. Ann Rheum Dis. 2002;61(6):554-8 Available from: http://www. pubmedcentral.nih.gov/articlerender.fcgi?artid=1754137\&tool= pmcentrez\&rendertype=abstract. [cited 2011 Oct 11].

23. OCEBM Levels of evidence working group, et al. "The Oxford 2011 Levels of Evidence". Oxford Centre for Evidence-Based Medicine. 2011. http://www. cebm.net/index.aspx?o=5653.

24. The Joanna Briggs Institute. Critical appraisal tools. 2018.

25. Navazesh M. Methods for collecting saliva. Ann N Y Acad Sci. 1993;694(1): 72-7.

26. Vitali C, Bombardieri S, Moutsopoulos HM, Balestrieri G, Bencivelli W, Bernstein RM, et al. Preliminary criteria for the classification of Sjögren's syndrome. Results of a prospective concerted action supported by the European community. Arthritis Rheum. 1993;36(3):340-7.

27. Herrera JL, Lyons MF, Johnson LF. Saliva: its role in health and disease. J Clin Gastroenterol. 1988;10(5):569-78.

28. Han P, Suarez-Durall P, Mulligan R. Dry mouth: a critical topic for older adult patients. J Prosthodont Res. 2015;59:6-19.

29. Furness $\mathrm{S}$, Bryan $\mathrm{G}, \mathrm{Mcmillan} \mathrm{R}$, Hv W. Interventions for the management of dry mouth: non- pharmacological interventions (Review). Cochrane Database Syst Rev. 2013;8.(Art.No.: CD009603:1-38.

30. Shiboski CH, Shiboski SC, Seror R, Criswell LA, Labetoulle M, Lietman TM, et al. 2016 American College of Rheumatology/European league against rheumatism classification criteria for primary Sjögren's syndrome: a consensus and data-driven methodology involving three international patient cohorts. Arthritis Rheumatol. 2017:69(1):35-45.

31. Flink $H$, Tegelberg $\AA$, Lagerlöf F. Influence of the time of measurement of unstimulated human whole saliva on the diagnosis of hyposalivation. Arch Oral Biol. 2005:50(6):553-9.

32. López-pintor RM, Casañas E, González-serrano J, Serrano J, Ramírez L, De Arriba $L$, et al. Xerostomia, Hyposalivation, and salivary flow in diabetes patients. J Diabetes Res. 2016;2016:1-16.

\section{Publisher's Note}

Springer Nature remains neutral with regard to jurisdictional claims in published maps and institutional affiliations.

Ready to submit your research? Choose BMC and benefit from:

- fast, convenient online submission

- thorough peer review by experienced researchers in your field

- rapid publication on acceptance

- support for research data, including large and complex data types

- gold Open Access which fosters wider collaboration and increased citations

- maximum visibility for your research: over $100 \mathrm{M}$ website views per year

At BMC, research is always in progress.

Learn more biomedcentral.com/submissions 